Sweller et al. (2010) state that problem solving cannot be taught independently of basic tools and basic thinking. Over time, students build up a repertoire of problem-solving techniques. Ultimately, the difference between someone who is good and someone who is bad at solving nonroutine problems is not that the good problem solver has learned to solve novel, previously unseen problems. It is more the case that, as students increase their expertise, more nonroutine problems appear to them as routine.

\section{References}

MARY DOLCIANI, S. L. BERMAN, and J. FreILICH (1962), Modern Algebra, Book 1, Houghton Mifflin Co. Boston, MA.

Ken B. Henderson and R. E. Pingry (1953), Problem solving in mathematics, The Learning of Math- ematics: Its Theory and Practice (H. F. Fehr, (ed.), Washington, D.C., National Council of Teachers of Mathematics, pp. 228-370.

MARgRet A. HJALMARSON and HeIDI DiEFES-DuX (2008), Teacher as designer: A framework for teacher analysis of mathematical model-eliciting activities, Interdisciplinary Journal of Problembased Learning, Vol. 2, Iss. 1, Article 5. Available at http://dx.doi.org/10.7771/15415015.1051.

John Sweller, R. Clark, and P. Kirschner (2010), Teaching general problem-solving skills is not a substitute for, or a viable addition to, teaching mathematics, Notices of the American Mathematical Society, Vol. 57, No. 10, November 2010. http://www.ams.org/notices/201010/ rtx101001303p.pdf

\title{
In Memory of Professor Francisco Federico Raggi Cárdenas
}

\section{María José Arroyo, Rogelio Fernández-Alonso González, Sergio R. López-Permouth, José Ríos Montes, and Carlos Signoret}

Professor Francisco Federico Raggi Cárdenas passed away June 12, 2012, in Mexico City. Professor Raggi was born in Mexico City in 1940. He obtained his undergraduate degree from Universidad Nacional Autónoma de México (UNAM), a master's degree from Harvard, and a doctorate from UNAM. In 1962 he joined the Institute of Mathematics of UNAM, where he worked until his passing. He held visiting positions in universities throughout

María José Arroyo is professor of mathematics at Universidad Autónoma Metropolitana Iztapalapa. Her email address is mja@xanum.uam.mx.

Rogelio Fernández-Alonso González is professor of mathematics at Universidad Autónoma Metropolitana Iztapalapa. His email address is rojo99@prodigy. net. mx.

DOI: http://dx.doi.org/10.1090/noti1052 the world, including institutions in Germany, the United States, Belgium, Canada, Spain, and Italy.

Professor Raggi taught modern algebra at all levels to many generations of students in Mexico. In particular, he had four Ph.D. students. Raggi was author or coauthor of five books that are prominently used in universities throughout Mexico. As he traveled constantly and taught at many places throughout Mexico, Raggi's commitment to the

Sergio R. López-Permouth is professor of mathematics at Ohio University. His email address is 1opez@ohio.edu.

José Ríos Montes is professor of mathematics at Universidad Nacional Autónoma de México. His email address is jrios@matem.unam.mx.

Carlos Signoret is professor of mathematics at Universidad Autónoma Metropolitana Unidad Iztapalapa. His email address is casi@xanum.uam.mx. 
development of mathematics in his country was unequivocal.

Professor Raggi was a man of principles; he was widely recognized for his integrity and trustworthiness. He will be remembered as a fun-loving, friendly person who loved his family, art, good food, music, movies, and science fiction. Everyone who knew him agrees that he was a wonderful conversationalist with whom it was very enjoyable to talk for hours about any imaginable topic.

Professor Raggi was involved in the organization of special sessions of most joint meetings of the American Mathematical Society and the Sociedad Matemática Mexicana (SMM). Professor Raggi was one of the pioneers in the introduction of ring theory to Mexico; his focus on the subject was from a lattice-theoretic perspective. He was the author of thirty-eight research articles. His work had four main streams:

1) Ring arithmetic theory and group rings. Raggi's first works are dedicated to the study of the group of units of certain rings. They were published in Spanish and constituted the basis for his Ph.D. thesis. These papers have many citations, such as the classic books Commutative group algebras, by Karpilovski, and Topics in group rings, by Sehgal.

2) Lattices associated with the category of $R$-modules and hereditary torsion theories. Raggi was interested in the general theory of localization, introduced by Gabriel, and related concepts such as Gabriel topologies, hereditary torsion theories, and left exact radicals. Some of the papers are cited by Golan in his book Torsion Theories. Raggi also studied nonhereditary torsion theories, which form a lattice that is not necessarily a set, and related this lattice with the lattice of hereditary torsion theories.

3) Dimension theory for rings, defined for several classes of modules. Raggi was interested in the Krull dimension, as defined by Gordon and Robson. He defined the finite length dimension and compared it with the Krull dimension and the dual Krull dimension. He also studied Serre subcategories.

4) The big lattice of preradicals over a ring. In 2002 Raggi considered for the first time the big lattice of preradicals over a ring from the lattice theory point of view. In the paper "The lattice structure of preradicals" it is proven that the lattice of preradicals is atomic and coatomic, describing the sets of atoms and coatoms. Using this lattice structure, he characterized semisimple Artinian rings, V-rings, and rings which are a finite product of simple rings. In other papers Raggi studied operators and partitions induced by them. He also defined prime preradicals and prime submodules of a module, relating both concepts. In one of his last works, Raggi defined the concept of a main injective module, whose fully invariant submodules are in bijective correspondence with all the left exact preradicals. In another paper he considered the case when the ring itself is a main injective module and proved that this occurs precisely when it is a QF ring.

The Sociedad Matemática Mexicana (SMM) honored Raggi posthumously with a memorial in his honor during their national meeting in Queretaro, Mexico, on October 30, 2012.

\section{About the Cover \\ Can mathematics help resolve serious conflicts?}

The idea and some images for this month's cover were taken from the article "Principles for implementing a potential solution to the Middle East conflict" by Thomas L. Saaty and H. J. Zoffer in this issue. They make an intriguing proposal. In a way, it is just an application of the standard technique for solving mathematical problems: break a large problem down into smaller ones.

$$
\begin{array}{r}
\text {-Bill Casselman } \\
\text { Graphics Editor } \\
\text { (notices-covers@ams.org) }
\end{array}
$$

The photo of the Palestinian refugee camp (lower right) is (c) Mohammed Asad/ Apaimages/ZUMA Press/Corbis. 